\title{
Risk of knee replacement after anterior cruciate ligament injury: a systematic review
}

\author{
Milan Duong Nguyen ( $\nabla$ milan.nguyen@hotmail.no) \\ Universitetet i Oslo https://orcid.org/0000-0003-2864-3334 \\ Asbjørn Årøen \\ Akershus Universitetssykehus HF
}

Research article

Keywords: anterior cruciate ligament injury, ACL injury, knee replacement, arthroplasty

Posted Date: June 8th, 2020

DOI: https://doi.org/10.21203/rs.3.rs-32044/v1

License: (c) (i) This work is licensed under a Creative Commons Attribution 4.0 International License. Read Full License 


\section{Abstract}

BACKGROUND: It is recognized that patients suffering rupture of the anterior cruciate ligament $(\mathrm{ACL})$ are prone to accelerated osteoarthritis (OA), thus, this patient group is at increased risk of undergoing knee replacement (KR) at a younger age compared to the general population. There are limited data directly determining the risk of $\mathrm{KR}$ in ACL-injured patients. The purpose of this study is to estimate the risk of undergoing $\mathrm{KR}$ in patients with a history of primary ACL injury (ACLi).

STUDY DESIGN: Systematic review.

METHODS: A systematic literature search with keywords and MeSH terms was performed using PubMed and Cochrane Library. We identified all studies reporting KR as an outcome in individuals with primary ACLi. Individuals with concomitant and secondary intra-articular injuries were included. A modified version of the Coleman Methodology Score (CMS) was used to evaluate the quality of the included studies. The risk was estimated by using the total number of ACL-injured patients and the total number of KRs within this cohort, consisting of both patients with reconstruction and patients with non-operative treatment.

RESULTS: A total of 152390 ACL-injured patients and a total of $1071 \mathrm{KRs}$ were assembled from 5 prospective and 7 retrospective studies, which revealed a mean modified CMS of 70. Mean follow-up time was 16 years (ranging from 4.6 to 30 years). Mean age among the patients was 29.8 years. Estimated risk of undergoing KR after ACLi was $0.7 \%$ with values between $0.54 \%$ and $9.5 \%$ among the included studies.

CONCLUSION: This systematic review suggests an estimated risk of KR among ACL-injured patients to be $0.7 \%$. Our findings are based on the results from the included studies, which, to some degree, showed divergence. The discrepancy may be due to variability in several factors, both research variables and patient factors, including follow-up time, sample size, subsequent injuries, obesity, sex, age and activity level. No consensus about OA development after ACLi has been established, however, OA is a common topic in the conversation between the doctor and the patient. This data may be helpful for physicians and clinicians when informing patients about the long-term risk of symptomatic $O A$, eventually requiring $K R$.

\section{Background}

\subsection{Anterior cruciate ligament injury}

The anterior cruciate ligament $(\mathrm{ACL})$ is an important stabilizing ligament of the knee, frequently injured due to an acute non-contact deceleration injury, forceful hyperextension or excessive rotational forces about the knee (1-3). Anterior cruciate ligament injury (ACLi) is the most frequent severe knee injury worldwide (4), commonly occurring in athletes and during sports involving sudden stops or changes in direction, jumping and landing, such as soccer, handball, basketball and downhill skiing (5). However, isolated ACLi is uncommon (6), as it is frequently associated with meniscal and chondral injuries, which 
have an impact on both short- and long-term outcomes (7). Excessive anterior translation and rotation of the tibia on the femur are primarily restrained by the $A C L$, thus, a completely torn ACL typically results in the sensation of knee instability or weak knees, commonly described as the knee "giving out" (8-10). ACLi affects the kinematics in the knee, significantly because of the increased anterior tibial translation, causing shearing forces applied mainly on the medial side of the knee (11).

According to the Norwegian National Knee Ligament Registry (NKLR), the annual rate of ACLi in Norway is estimated to be 4000 . In 2018, 1856 primary anterior cruciate ligament reconstructions (ACLRs) and 206 revisions were reported, which remains relatively unchanged from 2017 (1893/215). The pivoting sports soccer and handball cause a majority of ACLi events; the incidence is probably due to these sports being the most popular sports in Norway. Within soccer and handball, there are more females than males sustaining ACLi and undergoing ACLR, which correlates with the fact that female sex is a risk factor for ACLi. However, recent data suggests that this difference is present between 16 and 20 years of age, after that there is no difference between the two sexes. In the report from NKLR (2019), a large number of patients undergoing surgical reconstruction are younger than 20 years of age $(12,13)$.

An ACLi has an impact on sports participation and may be disastrous for athletes. Findings from a comprehensive systematic review by Ardern et al. (2014), suggest that $55 \%$ of athletes return to competitive sport after ACLR (14). In a study by Roos et al. (1995), analyzing elite soccer players, none of the ligament-injured elite players returned to pre-injury level after 7 years, compared to $30 \%$ in a control group of elite players with normal knees, indicating unsatisfactory results of current treatment methods for patients with high activity demands (15). Furthermore, knee-related quality of life (QoL) is commonly impaired 5-25 years after onset of ACLi in ACL-injured individuals, irrespective of management strategy, compared to population norms (16).

\subsection{Treatment of anterior cruciate ligament injury}

It is common among both patients and knee surgeons to believe that ACLR prevents osteoarthritis (OA), but treatment of $A C L i$ is controversial, with many conflicting aims, such as a wish to return to pre-injury level, prevent subsequent meniscal tear (MT) and protect against knee OA $(15,17)$. There exist a few reports on healing of ruptured ACL (18), however, the patients generally have to live with the disability caused by this serious knee injury, and furthermore, according to insurance companies, ACLi causes a 5 $\%$ disability in the long run, irrespective of preferred treatment (19).

Acute primary repair after rupture of the ACL was previously a common surgical procedure (20), and it has recently become popular again. ACLR has been used to restore the injured knee to a more stable state, however, there is insufficient evidence to support a protective role of ACLR against OA development (6). Furthermore, findings in a systematic review by Øiestad et al. (2009) were conflicting (21). The first high quality randomized controlled trial by Frobell et al. (2010) comparing surgical and non-surgical treatment strategies in young active adults with an acute ACLi, found no differences at 5 years between reconstructed knees and those treated with rehabilitation alone (22). This needs to be considered when advising patients about the management after ACLi, as most athletes undergo surgical intervention with 
the aim of enabling return to sports by restoring knee stability and function (23-25). Filbay et al. (2015) identified no significant difference in knee-related QoL between reconstructed patients and conservatively managed patients (16).

On the contrary, a recent study by Sanders et al. (2016) comparing reconstructed patients and patients treated non-operatively with a mean follow-up time of 13.7 years, found that ACLR significantly reduced the risk of secondary MT and OA compared with non-surgical treatment. The authors of this study criticize the short follow-up time in the study by Frobell et al. (2010), as the results of their analysis demonstrate that there is little difference in arthritis between patients treated with ACLR and nonoperatively treated patients until approximately 6 years after ACLi. Additionally, non-operatively treated patients were 5 times more likely to sustain secondary MT than reconstructed patients (26). A comment on the study by Frobell et al. (2010) from Løken et al. (2011) also addresses the 5-year follow-up as a weakness, bringing up the subject of long-term results (27). In the unstable knee, reconstruction may prevent subsequent injuries by reestablishing sufficient functional stability (28), indirectly protecting against accelerated knee $\mathrm{OA}$, but reconstruction is listed as an arthrogenic factor, as it is possible that the procedure can kick-start the development of OA (11). A systematic review by Sommerfeldt et al. (2018) found a high incidence of knee OA after ACLi, which partially may be explained by the fact that an ACLdeficient knee is more prone to subsequent damage to cartilage and menisci (29). Moreover, a recent study by Lindanger et al. (2019) concludes with an increased risk of KR among patients with late ACLR ( $\geq 24$ months) compared to the group with early ACLR (30). There is a lack of evidence regarding the superior treatment due to the discrepancy in available literature. Treatment of ACLi remains controversial in 2020 .

\subsection{Knee osteoarthritis}

$\mathrm{OA}$ is a common degenerative disorder characterized by loss of cartilage in the joints with past trauma as a risk factor. Other risk factors include advancing age, obesity, genetics and female sex. Age is the strongest predictor of radiographic OA development and progression. The prevalence of joint pain is markedly increased with age in the general population. OA is primarily a clinical diagnosis; the association between radiographic features of OA and joint pain is not constant (31-33).

\subsubsection{Traumatic knee injuries accelerate knee osteoarthritis development}

A key concern after knee injuries is the development of OA. Knee OA is a significant cause of impaired mobility (33). Progression of knee OA is slow, generally taking several years. Acute joint injuries, such as ACLi and MT, provide a greater risk of early development of knee OA. It is widely accepted that joint instability following ACLi causes meniscal lesions, and that meniscectomy, which results in loss of the load-bearing and shock-absorbing functions of the menisci, is associated with accelerated OA development (34-38). Long-term changes, such as disruption of normal mechanics in the joint and altered load distributions, come in addition to the intra-articular pathogenic processes initiated at the time of injury, contributing to the increased incidence of later OA (32). Furthermore, Khan et al. (2019) did the first epidemiological study in quantifying the important link between ACLi and MT and end-stage OA treated 
by total knee replacement (TKR). They found an estimated 7-fold and 15-fold increased odds for TKR after ACLi and MT, respectively, when compared to an age-matched cohort, which demonstrates that ACLi and MT are significant independent risk factors for end-stage OA requiring TKR. Patients undergoing TKR after ACLi or MT were found to be significantly younger at the time of surgery than individuals without these injuries (39).

Additional individual variables, including genetics, sex, age, muscle strength, obesity, activity level and reinjury, contribute to variation in outcome. As a majority of individuals with acute ACLi are younger than 30 years at onset of injury, and several of them under 20 years, ACLi is responsible for a high quantity of patients with early-onset $\mathrm{OA}$, contributing to associated pain, functional limitations and reduced QoL in the patient group between 30 and 50 years of age; the young patient with the old knee (6).

Roos et al. (1995) states that ACL rupture, isolated or with concomitant injuries to the menisci or collateral ligaments, results in radiologic changes indicating OA in $60-90 \%$ of these patients $10-15$ years after injury (40-45), however, comparisons are uncertain due to different criteria for radiologic $O A$, as well as the small numbers of patients in the respective studies (46). Moreover, a later study by Lohmander et al. (2007), suggests that, on average, $50 \%$ (ranging from 10-90\%) of those with a diagnosed ACLi or MT have $\mathrm{OA}$ with associated pain and functional impairment 10-20 years after the diagnosis (6).

In a review of risk factors of $O A$ in $A C L$-injured patients, the authors list possible factors contributing to the origin of OA in patients with ACLi: (1) concomitant damage to menisci, articular cartilage and ligaments, (2) subsequent (traumatic) injuries due to instability and "giving way", which have an impact on the menisci and cartilage, as well as possibly stretching peripheral ligamentous structures and (3) chronic injury as a result of alterations in the biomechanics due to shearing forces affecting the articular cartilage (11).

\subsubsection{Radiographic diagnosis}

No universal methodological radiologic classification method exists (21), but the Kellgren-Lawrence system for radiographic diagnosis of OA has been the standard for many decades and is currently the most widely used clinical tool for radiographic grading of OA. Radiographic features, including osteophytosis, joint space narrowing (JSN), joint line sclerosis and subchondral cysts, are used to grade the $O A$ severity from 0 (normal joint) to 4 (complete joint space loss) $(47,48)$.

Table 1. Grade and characteristics according to Kellgren-Lawrence Classification of Osteoarthritis (47) 


\begin{tabular}{|ll|}
\hline Grade & Characteristics \\
\hline 0 & No JSN or reactive changes \\
1 & Doubtful JSN, possible osteophytic lipping \\
2 & Definite osteophytes, possible JSN \\
3 & Moderate osteophytes, definite JSN, some sclerosis, possible bone-end deformity \\
& Large osteophytes, marked JSN, severe sclerosis, definite bone ends deformity \\
\hline
\end{tabular}

\subsubsection{The Knee Injury and Osteoarthritis Outcome Score}

The Knee Injury and Osteoarthritis Outcome Score (KOOS), a knee-specific, self-administered instrument, developed as an extension of the WOMAC Osteoarthritis Index (49), assesses the patients' opinion about their knee and associated problems. Evaluating short-term and long-term symptoms and function in subjects with knee injury and OA, the KOOS holds 42 items in 5 separately scored subscales: Pain, Other Symptoms, Function in daily living (ADL), Function in Sport and Recreation (Sport/Rec) and knee-related QoL (50).

\subsubsection{High physical activity as a risk factor}

There is an association between participating in elite sports and an increased risk of OA. The degree of risk is dependent on the nature of the sport. Sports that involve high intensity and repetitive and high impact forces through the affected joints provide the greatest risk (51). In a review of risk factors for OA in patients with ACLi from Louboutin et al. (2009), a summary of OA rates in a small cohort of 19 elite athletes following ACLi is presented (figure 1); all had degenerative changes by 35 years and $42 \%$ ( 8 out of 19) had undergone TKR (editor's note: according to the original study (52), 10 out of 19 had undergone TKR by 35 years). Additionally, all athletes had medial meniscectomies by 20 years (11).

Moreover, von Porat et al. (2004) found a prevalence of radiographic knee OA of $41 \%$ in male soccer players 14 years after ACLi, irrespective of the treatment provided, often severely affecting knee-related QoL (53). Similarly, results from a cohort of female soccer players between 26 and 40 years of age sustaining ACLi 12 years earlier, showed that more than $50 \%$ of the participants had radiographic OA in their injured knee (54).

Even after ACLR, there is a 30-40 times greater risk of re-rupture in a young patient returning to sport, compared with an uninjured counterpart (55). According to a report from NKLR, hazard ratios for revision and contralateral ACLR for the 15-19 year age group are 4.0 and 4.9, respectively, compared with the patient group over 30 years of age, making young patients sustaining ACLi at greater risk of earlier post- 
traumatic osteoarthritis (PTOA) due to additional OA risk factors, which in this case are re-rupture and contralateral ACLi (56).

\subsubsection{Prevalence of knee OA in Norway}

From a population survey in Norway, looking at hand, hip and knee OA, the overall prevalence of knee OA was $7.1 \%$ (57). A strength of this study is the limited geographical area, as all subjects were inhabitants of the Ullensaker municipality, making the population relatively homogenous. However, there are geographical differences, as the prevalence of OA among men is higher in the countryside, possibly explained by more heavy manual work in these areas (58).

Table 2. Adapted from Grotle et al. (2008). Knee OA in a Norwegian population-based study showing prevalence (frequency with percentage in parentheses) of OA in knee according to sex and age groups (57)

\begin{tabular}{|llll|}
\hline Group & Age, years & Knee OA, $\mathrm{n}=92$ & Kemale \\
\hline $1928-30$ & $74-74$ & $18(14.9)$ & $37(28.2)$ \\
$1938-40$ & $64-66$ & $31(14.0)$ & $38(16.1)$ \\
$1948-50$ & $54-56$ & $26(8.3)$ & $39(10.5)$ \\
$1958-60$ & $44-46$ & $10(3.6)$ & $16(4.9)$ \\
$1968-70$ & $34-36$ & $7(1.7)$ & $10(1.8)$ \\
$1978-80$ & $24-26$ & 0 & $1(0.6)$ \\
\hline
\end{tabular}

\subsection{Knee replacement}

Knee replacement (KR), including unicompartmental knee replacement (UKR) and TKR, is an effective surgical intervention for end-stage OA, and is commonly performed (59). TKR has become the gold standard for management of disability and persistent pain associated with knee OA (60). KR is an increasingly common procedure, possibly due to an increasingly ageing society, as well as rising rates of obesity, causing an inevitable increase in rates of knee OA, which is the main clinical indication for TKR. One study suggest the lifetime risk of TKR for individuals over 50 years of age to be $8.1 \%$ for men and as high as $10.8 \%$ for women (61). Generally, patients undergoing KR have end-stage OA, but the decision to go under the knife should be guided by the patient's symptoms, although there is no consensus on the severity level of symptoms regarding surgery indication $(62,63)$. The radiologic rate of OA after ACLi is noticeably higher than the symptomatic rate, still the latter is the most crucial to the patient (11). Overall, $K R$ is a powerful and evident surrogate endpoint for severe $O A(64,65)$. 
$7000 \mathrm{KR}$ procedures are annually performed in Norway. The number is increasing, and it has been doubled from 2005-2018. The majority of patients have OA with a mean age of 69 years for women and 67 years for men when undergoing KR. $63 \%$ of the patients are women. In 2018, 223 KR procedures were due to sequelae after ligament injury (66).

A study by Leroux et al. (2014) comparing cumulative incidence of KR between patients with ACLR and a non-injured control group, found the cumulative incidence of KR following cruciate ligament reconstruction after 15 years to be low (1.4\%), however, it was 7 times greater than the matched control subjects from the general population (0.2\%) (59). There are few existing studies analyzing KR as an outcome in ACL-injured patients. The purpose of this systematic review was to estimate the risk of undergoing KR among patients with a history of primary ACLi with or without subsequent lesions.

\section{Methods}

\subsection{Search strategies}

Systematic research started January 2019 in PubMed and Cochrane Library. Relevant MeSH terms for the topics "anterior cruciate ligament injury" and "knee replacement" were looked up using PubMed's MeSH database. Different search techniques were used to narrow the results and find the most relevant articles: truncation was added to the word stem to find the plural variations of a word, i.e. injur* includes both injury and injuries, quotation marks were used to keep terms together and in order, i.e. "knee replacement" vs. knee replacement, parentheses for combining concepts and the Boolean operators AND and OR were used to connect and define the relationship between the search terms.

Using the advanced search page in PubMed, each topic was searched separately before combining them together in one search: ("anterior cruciate ligament injur*" OR "anterior cruciate ligament rupture" OR "anterior cruciate ligament tear" OR "ACL injur*" OR "ACL rupture" OR "ACL tear") AND ("knee replacement" OR "joint replacement" OR arthroplast*). The same search strategy was performed in Cochrane Library. The number of studies included in this thesis increased after updating the search December 2019, as well as after reviewing the reference lists of the relevant studies.

\subsection{Study selection}

We included any study reporting KR, both UKR and TKR, in patients with history of primary isolated ACLi; however, concomitant collateral ligament sprains and meniscal injuries were also included, as this will be a part of the primary injury resembling the impact of soft tissue injuries on the outcome of a fracture. Due to no consensus regarding the long-term protective role of ACLR against knee OA, we decided to merge patients with ACLR and patients without ACLR, which represented one case group in our study.

Since $O A$ is an age-related disease, studies reporting the cohort with mean age over 50 years were excluded. Other exclusion criteria were age under 15 years when sustaining ACLi, previous knee injury and previous knee surgery. Having a previous knee injury/surgery would have an impact on the outcome that 
would affect the interpretation regarding the role of ACLi; the more injuries to the joint, the greater the risk of accelerated knee OA. We wanted to see the relation between rupture of ACL and KR, hence, we included only subjects with primary ACLi with or without subsequent injuries. As already commented on, subjects with secondary damage, such as MT and re-ruptures, were not excluded, as it is recognized that ACLinjured patients are at an increased risk, and furthermore, to capture the infrequent event of KR.

Table 3. Inclusion and exclusion criteria

\begin{tabular}{|l|}
\hline Inclusion criteria \\
Primary isolated ACL injury \\
Minimum follow-up time $=2,5$ years \\
Exclusion criteria \\
Previous knee injury \\
Previous knee surgery \\
$<15$ years old at onset of injury \\
Mean age $>50$ years old \\
\hline
\end{tabular}

Nebelung et al. (2005) looked at the incidence and progression of OA over a time period of 35 years following ACLi in high-level athletes. The study's results showed that the odds of having KR within this patient group was $52 \%$ (10 out of 19 athletes underwent arthroplasty) (52). We decided to exclude this study in our review, as the rate of OA progression following knee injury is accelerated in this otherwise healthy, high-demand patient population (11). Thus, including a study examining a patient group consisting exclusively of high level athletes would have given a too high risk when determining the risk of $\mathrm{KR}$ in patients with activity level at an average level, although we are aware of the fact that a large number of ACLi happen during sports activities and that an estimated $55 \%$ return to their pre-injury activity level (14).

Similarly, Meehan et al. (2018) enrolled a cohort of former National Football League players who played since 1960 to assess potential long-term health consequences associated with participating in the sport, including whether ACL tears were associated with later life co-morbidities. According to this study, the risk of KR among players with ACLR was as high as $62,4 \%$ (490 KRs out of 692 players with ACLi) (67), which is remarkably higher than previous studies that do not look at a specific group of patients. This corresponds to what we already know about the activity level's impact on the development of OA, especially pivoting sports.

However, we included a study examining exclusively ACL-injured patients with secondary MT (Hagmeijer et al. 2019), due to, as mentioned previously, the increased risk of MT within this patient group. Loss of meniscal integrity is a significant risk factor of developing $O A$, thus, including this study in our review contributes to a higher estimate regarding the risk of arthroplasty among ACL-injured patients. 
Table 4. Study design, MCMS and purpose for each included study listed by highest MCMS

\section{Text under table:}

${ }^{a}$ MCMS, Modified Coleman Methodology Score; ACLi, ACL injury; ACLR, ACL reconstruction; MT, meniscal tear; TKA, total knee arthroplasty; OA, osteoarthritis 


\begin{tabular}{|c|c|c|c|}
\hline Study & Study design & MCMS & Purpose of the study \\
\hline $\begin{array}{l}\text { Sporsheim } \\
\text { et al. } \\
(2019) \\
(68)\end{array}$ & $\begin{array}{l}\text { Prospective } \\
\text { randomized trial }\end{array}$ & 92 & $\begin{array}{l}\text { Compare the } 30 \text {-year follow-up results after treatment of } \\
\text { ACLi with } 3 \text { different surgical procedures }\end{array}$ \\
\hline $\begin{array}{l}\text { Elveos et } \\
\text { al. }(2018) \\
(69)\end{array}$ & $\begin{array}{l}\text { Randomized } \\
\text { controlled trial }\end{array}$ & 92 & $\begin{array}{l}\text { Compare } 25 \text {-year follow-up results after ACLR using a } \\
\text { bone-patellar tendon-bone (BPTB) graft with or } \\
\text { without the Kennedy LAD }\end{array}$ \\
\hline $\begin{array}{l}\text { Lindanger } \\
\text { et al. } \\
(2019) \\
(30)\end{array}$ & $\begin{array}{l}\text { Prospective } \\
\text { cohort study }\end{array}$ & 88 & $\begin{array}{l}\text { Examine the rate and level of return to pivoting sports } \\
\text { after ACLR, the duration of sports participation, and } \\
\text { long-term consequences of returning to pivoting sports }\end{array}$ \\
\hline $\begin{array}{l}\text { Gföller et } \\
\text { al. }(2019) \\
(70)\end{array}$ & $\begin{array}{l}\text { Prospective } \\
\text { cohort study }\end{array}$ & 77 & $\begin{array}{l}\text { Evaluate long-term clinical and radiological outcomes of } \\
\text { non-operative treatment of ACLi }\end{array}$ \\
\hline $\begin{array}{l}\text { Leroux et } \\
\text { al. }(2014) \\
(59)\end{array}$ & $\begin{array}{l}\text { Prospective } \\
\text { population- } \\
\text { based matched } \\
\text { cohort study }\end{array}$ & 72 & $\begin{array}{l}\text { Determine the risk of arthroplasty following cruciate } \\
\text { ligament reconstruction, and to identify patient, provider, } \\
\text { and surgical factors that influence knee arthroplasty risk }\end{array}$ \\
\hline $\begin{array}{l}\text { Hagmeijer } \\
\text { et al. } \\
(2019) \\
(71)\end{array}$ & $\begin{array}{l}\text { Retrospective } \\
\text { cohort study }\end{array}$ & 70 & $\begin{array}{l}\text { Describe the rates and natural history of secondary } \\
\text { meniscal tears after ACLi and to determine the effect of } \\
\text { MT treatment on the development of OA and conversion } \\
\text { to TKA }\end{array}$ \\
\hline $\begin{array}{l}\text { Abram et } \\
\text { al. }(2019) \\
(72)\end{array}$ & $\begin{array}{l}\text { Case-control } \\
\text { study }\end{array}$ & 70 & $\begin{array}{l}\text { Risk of arthroplasty in ACL reconstructed patients } \\
\text { through comparison with the general population }\end{array}$ \\
\hline $\begin{array}{l}\text { Singhal et } \\
\text { al. (2007) } \\
\text { (73) }\end{array}$ & $\begin{array}{l}\text { Retrospective } \\
\text { cohort study }\end{array}$ & 58 & $\begin{array}{l}\text { Evaluate the outcome of ACLR via anterior tibialis } \\
\text { tendon allograft }\end{array}$ \\
\hline $\begin{array}{l}\text { Sanders et } \\
\text { al. }(2017) \\
(74)\end{array}$ & $\begin{array}{l}\text { Case-control } \\
\text { study }\end{array}$ & 57 & $\begin{array}{l}\text { (1) Compare the risk of subsequent MT and OA between } \\
\text { patients with isolated ACLi treated without ligament } \\
\text { reconstruction and a matched cohort of individuals } \\
\text { without ACLi } \\
\text { (2) Examine factors predictive of long-term sequelae } \\
\text { after non-operative treatment of isolated ACL tears }\end{array}$ \\
\hline $\begin{array}{l}\text { Sanders et } \\
\text { al. (2016) } \\
(26)\end{array}$ & $\begin{array}{l}\text { Retrospective } \\
\text { cohort study }\end{array}$ & 57 & $\begin{array}{l}\text { (1) Evaluate the protective benefit of ACLR in preventing } \\
\text { subsequent MT or OA } \\
\text { (2) Determine if earlier ACLR offers greater protective } \\
\text { benefits than delayed reconstruction } \\
\text { (3) Evaluate factors predictive of long-term sequelae } \\
\text { after ACLR }\end{array}$ \\
\hline $\begin{array}{l}\text { Lin et al. } \\
(2017) \\
(75)\end{array}$ & $\begin{array}{l}\text { Retrospective } \\
\text { cohort study }\end{array}$ & 55 & $\begin{array}{l}\text { Support the potential protective role of ACLR against the } \\
\text { development OA }\end{array}$ \\
\hline $\begin{array}{l}\text { Boyle et } \\
\text { al. }(2019) \\
(76)\end{array}$ & $\begin{array}{l}\text { Retrospective } \\
\text { cohort study }\end{array}$ & 50 & $\begin{array}{l}\text { Long-term functional outcomes of revision ACLR with } \\
\text { autograft and factors that influence the outcomes }\end{array}$ \\
\hline
\end{tabular}

Page 11/29 


\subsection{Flow diagram}

\subsection{Data extraction}

To estimate the risk of KR among patients with a history of ACLi, the number of ACL-injured patients and the number of KRs within this patient group extracted from each included study, were incorporated to get a total number of ACL-injured patients and a total number of KRs. Mean follow-up time, mean age and percentage of male within the cohorts were reported. One study (59) did not state mean age; the author of this systematic review manually calculated the mean age using the information provided.

\subsection{Quality assessment}

In evaluating the quality of the included studies, we used the methodology score introduced by Coleman et al. (77), which was later modified by Jakobsen et al. (78) (Appendix 1). The Coleman Methodology Score (CMS) originally consisted of 10 criteria and was developed to assess clinical studies on surgical treatment of patellar and achilles tendinopathy with a total score ranging from 0-100 $(21,79)$. Achieving a score of 100 indicates that the study contains minimally confounders and other biases. The difference between the original CMS and the Modified Coleman Methodology Score (MCMS), is that MCMS describes the post-operative rehabilitation, while CMS only evaluates compliance of the rehabilitation protocol among the participants (80).

Since no cutoff for MCMS to define high or low methodological quality has been reported (21), we decided, after assessing the quality of the eligible studies, giving us a subjective impression of acceptable quality, that a minimum score of 50 was required to be included. The literature suggests a score of more than $55 \%$ for other checklists to be considered as high quality (81), thus, we consider a minimum score of 50 to be reasonable. We are aware that the scoring system may be subject to different interpretations, as some of the criteria was not clearly defined, thus, the scoring is prone to subjectivity and the score outcome is dependent on the investigator.

\subsection{Statistical analysis}

By combining the number of patients with ACLi from all of the eligible studies and the number of KRs within this patient group, we estimated the risk of undergoing KR after suffering an ACLi. After reviewing the included individual studies, a total of $152390 \mathrm{ACL}$ ruptures and $1071 \mathrm{KRs}$ were included in our calculation. As mentioned previously, our cohort consisted of both patients with ACLR and patients with non-operative treatment; we estimated a combined risk of KR for these two patient groups. In addition, 95 $\%$ confidence interval $(\mathrm{Cl})$ was calculated for each study

\section{Results}

Using the search strategies in PubMed and Cochrane Library, as well as reviewing the reference lists in relevant studies, abstracts of a total of 356 studies were reviewed, resulting eventually in 12 included 
studies. The study included from a reference list (59) did not appear in the systematic searches because of the missing citation terms "anterior cruciate ligament injur*/tear/rupture" or "ACL injur*/tear/rupture". Studies reporting KR as an outcome among patients with a history of primary ACLi, with or without ACLR, were included. Figure 2 shows the flow diagram illustrating the study selection. The characteristics of the included studies are presented in table 5 .

Table 5. Study, sample size, percentage of male within the cohort, mean follow-up time, mean age, reported risk factors, KR events

Text under table:

${ }^{a} \mathrm{KR}$, knee replacement; $\mathrm{OA}$, osteoarthritis; $\mathrm{ACL}$, anterior cruciate ligament; $\mathrm{ACLi}$, anterior cruciate ligament injury; ACLR, anterior cruciate ligament reconstruction; rACLR, revision anterior cruciate ligament reconstruction; PCLR, posterior cruciate ligament reconstruction; rCLR, revision cruciate ligament reconstruction; $\mathrm{MCL}$, medial collateral ligament

${ }^{b}$ Percentage of KRs among ACL-injured patients

CDamage and procedures in addition to primary ACL injury with or without ACLR

${ }_{\mathrm{r}} \mathrm{rCLR}$ and primary PCLR represented $<2 \%$ of all cruciate ligament reconstruction cases included in this study

ePatients with ACLi enrolled between January 1996 and December 2013

fPatients requiring secondary interventions during follow-up were discarded as the purpose of the study was to analyze objective and subjective outcomes of ACL-deficient patients over 20 years

gMean age for patients with early ACLR was 23 years old. Men age for patients with late ACLR was 27.3 years old 


\begin{tabular}{|c|c|c|c|c|c|c|}
\hline$y$ & $\begin{array}{l}\text { No. of } \\
\text { patients }\end{array}$ & $\begin{array}{l}\text { Male } \\
\text { sex, } \\
\%\end{array}$ & Mean follow-up time & $\begin{array}{l}\text { Mean } \\
\text { age }\end{array}$ & Reported risk factors $^{C}$ & $\begin{array}{l}\mathrm{KR}^{\mathrm{a}} \\
\text { events } \\
\left(\%{ }^{\mathrm{b}}\right)\end{array}$ \\
\hline $\begin{array}{l}\text { sheim } \\
(68)\end{array}$ & 113 & 56 & 30 years & $\begin{array}{l}30 \\
\text { years }\end{array}$ & $\begin{array}{l}\text { rACLR } \\
\text { Meniscal injury } \\
\text { MCL injury }\end{array}$ & $7(6.2)$ \\
\hline $\begin{array}{l}\text { js et } \\
\text { i9) }\end{array}$ & 93 & 45 & 25 years & $\begin{array}{l}26 \\
\text { years }\end{array}$ & $\begin{array}{l}\text { Information about } \\
\text { concomitant/secondary } \\
\text { injury not included }\end{array}$ & $7(7.5)$ \\
\hline $\begin{array}{l}\text { anger } \\
(30)\end{array}$ & 217 & 47 & 25 years & $\begin{array}{l}23 \text { and } \\
27.3 \\
\text { years }^{\mathrm{g}}\end{array}$ & $\begin{array}{l}\text { Meniscal injury } \\
\text { Chondral injury }\end{array}$ & $\begin{array}{l}11 \\
(5.1)\end{array}$ \\
\hline $\begin{array}{l}\text { er et } \\
\text { '0) }\end{array}$ & 41 & 71 & $\begin{array}{l}\text { Follow-up evaluations 5-7, 10- } \\
12 \text { and } 20-22 \text { years after } \\
\text { injury }^{\mathrm{f}}\end{array}$ & $\begin{array}{l}32.3 \\
\text { years }\end{array}$ & $\begin{array}{l}\text { Meniscal injury } \\
\text { MCL injury }\end{array}$ & $1(2.4)$ \\
\hline $\begin{array}{l}\text { ux et } \\
\text { i9) }\end{array}$ & 30301 & 65 & 15 years & $\begin{array}{l}35 \\
\text { years }\end{array}$ & $\begin{array}{l}\text { PCLR } \\
\text { rCLR } \\
\text { Meniscal injury }\end{array}$ & $\begin{array}{l}212 \\
(0.7)\end{array}$ \\
\hline $\begin{array}{l}\text { neijer } \\
(71)\end{array}$ & 196 & 64 & 18 years & $\begin{array}{l}28.9 \\
\text { years }\end{array}$ & Meniscal injury & $\begin{array}{l}18 \\
(9.2)\end{array}$ \\
\hline $\begin{array}{l}\mathrm{m} \text { et } \\
\text { '2) }\end{array}$ & 111212 & 77 & 5.9 years & $\begin{array}{l}29 \\
\text { years }\end{array}$ & $\begin{array}{l}\text { Meniscal injury } \\
\text { Chondral injury }\end{array}$ & $\begin{array}{l}600 \\
(0.54)\end{array}$ \\
\hline $\begin{array}{l}\text { hal et } \\
\text { '3) }\end{array}$ & 69 & 55 & 4.6 years & $\begin{array}{l}31.7 \\
\text { years }\end{array}$ & $\begin{array}{l}\text { Meniscal injury } \\
\text { Chondral injury }\end{array}$ & $1(1.5)$ \\
\hline $\begin{array}{l}\text { lers } \\
(74)\end{array}$ & 364 & 60.2 & 14.3 years & $\begin{array}{l}31.5 \\
\text { years }\end{array}$ & Meniscal injury & $\begin{array}{l}26 \\
(7.1)\end{array}$ \\
\hline $\begin{array}{l}\text { lers } \\
\text { (26) }\end{array}$ & 964 & 61 & 13.7 years & $\begin{array}{l}28.1 \\
\text { years }\end{array}$ & $\begin{array}{l}\text { Meniscal injury } \\
\text { Chondral injury }\end{array}$ & $\begin{array}{l}28 \\
(2.9)\end{array}$ \\
\hline $\begin{array}{l}\mathrm{t} \\
\text { '5) }\end{array}$ & 8769 & 56.7 & $\begin{array}{l}\text { Followed up from ACLi onset } \\
\text { until OA onset or the end of } \\
2013^{\text {e }}\end{array}$ & $\begin{array}{l}35.4 \\
\text { years }\end{array}$ & Meniscal injury & $\begin{array}{l}159 \\
(1.8)\end{array}$ \\
\hline $\begin{array}{l}\text { э et } \\
\text { '6) }\end{array}$ & 51 & 86.3 & 9 years & $\begin{array}{l}26.5 \\
\text { years }\end{array}$ & $\begin{array}{l}\text { Re-rupture } \\
\text { Re-revision ACLR } \\
\text { Meniscal injury } \\
\text { Chondral injury }\end{array}$ & $\begin{array}{l}1 \\
(1.96)\end{array}$ \\
\hline
\end{tabular}

\subsection{Methodological quality}

Table 4 presents the results of the quality assessment of the studies using MCMS. Overall, the quality of the included studies was of high-quality with a mean score of 70 (ranging from 50-92). None of the studies achieved the maximum score of 100 ; however, two studies $(68,69)$ revealed a MCMS of 92.

\subsection{Risk of undergoing KR}

The total number of participants was 152 390, with sample sizes ranging from 41 to 111212 patients. The total number of KRs was 1071. Risks ranged from $0.54 \%$ to $9.2 \%$ in the included studies. The risk of undergoing KR among ACL-injured patients was calculated by using the number of subjects and the number of KRs from each study to get a final sum, giving a risk of $0.7 \%(1071 / 152390)$.

\subsection{Demographic data}


Mean follow-up time, percentage of male included and mean age at onset of study for each included study are presented in table 5 . The study that did not report mean age (59), reported the median age to be 28 years, however, the mean age was manually calculated using the provided information about the percentage distribution among the age groups.

\section{Conclusion And Discussion}

The absolute rate of KR among ACL-injured patients varies in the literature. Though there is a reason to believe that this knee injury increases the general risk of $O A$ in the individual, which also is reflected in the disability score from the government from April 1997 (19). The variations may be due to variability in follow-up time and sample size in the studies, but also covariates including secondary injuries, interventions, rehabilitation protocol, age, sex, as well as modifiable factors such as activity level, BMI etc., which must be taken into consideration when interpreting the results. For instance, Hagmeijer et al. (2019) had the highest reported risk of KR, which most likely is explained by additional meniscal injury as inclusion criterion in their study, along with a small sample size. Study population size is a crucial consideration; research including larger sample size has a higher significance level of the findings (82). The standard error is determined by the sample size: the greater the selection, the less errors (83). Thus, larger sample sizes will provide more accurate values and reliable results, which are more likely to be representative of the population $(84,85)$. Sample size is of great importance when considering the significance of the findings, but another important factor when estimating the risk is follow-up time, as it takes several years to develop OA. Older age is the greatest risk factor for OA, but the disease severity is more often than not related to other risk factors of OA, e.g. joint injury, anatomical factors affecting joint mechanics, genetics and obesity (86). OA development in younger people is often due to an underlying reason, most likely as a direct result of a trauma (87). Thus, patients suffering ACLi have a higher risk of undergoing $\mathrm{KR}$ earlier, as well as an elevated lifetime risk of KR, due to accelerated OA development. The limited follow-up period in the included studies makes it difficult to determine the overall KR risk among patients with ACLi. It is highly possible that a longer follow-up time would have given an increased risk estimate. Nonetheless, it is always a certain risk of arthrosis in every human being; $\mathrm{OA}$ is an age-related disease and is generally present, to some degree, in individuals exceeding 60 years of age (48).

In this systematic review we found the estimated risk of undergoing KR among patients with a history of primary ACLi to be $0.7 \%$, which is consistent with the studies analyzing the largest samples $(59,72)$. Nevertheless, Abram et al. (2019) had both the least mean follow-up time and the largest sample size, which is noteworthy, as $O A$ is a degenerative condition and disabling OA could take years or even decades to develop (88). As mentioned previously, Sanders et al. (2016) mentioned that one of the weaknesses in other studies examining difference in OA development between ACLR patients and nonoperatively treated patients, was the follow-up time, as degenerative changes were not apparent until 6 years after the injury. Based on this, it is possible that the risk of KR among ACL-injured patients is underestimated in the study from Abram et al. (2019). Our method of estimating the risk was by combining all numbers, which may be a weakness, as the result from the study with the largest sample size can dominate and outweigh the findings of the other studies. 
The included studies are not comparable due to the great variability of several factors, both baseline characteristics and study variables, thus, stating a risk of KR is difficult. This study has several limitations. As mentioned previously, the estimated risk is applied for both patients with reconstruction and patients with non-operative treatment, thus, differences in graft types used in the group with ACLR were not taken into account. In 2020, it is our understanding that the protective role of ACLR is still uncertain. Additionally, we did not report the number of secondary injuries, nor whether meniscal repair or meniscectomy was performed, despite the fact that meniscectomy is proven to represent a significant risk factor for knee $O A(89,90)$, unlike meniscal repair, which is of great importance in preventing $O A$ development in the knee joint (91); preserving as much functional meniscal tissue as possible in surgical treatment of meniscal lesions is desirable (92).

Another limitation of significance is the use of different radiographic classification systems in $\mathrm{OA}$ diagnosis, in either isolation or in combination with symptomatology, when the decision to undergo joint replacement is made. Indications for undergoing KR were not consistently reported in the included studies, and radiographic or patients' reports about their symptoms were not available for analysis. Radiographic OA does not always reflect the severity of symptomatology; nonetheless, joint replacement does indicate severe symptomatic OA. Moreover, the included studies had different purposes (presented in table 4). Only one study had KR as main outcome (59). Whether this is of significance for our findings, is uncertain.

A trend of increasing incidence of ACLi and MT is observed $(93,94)$, and furthermore, according to a recent study, the rate of pediatric ACLi has been increasing approximately $2.3 \%$ annually for the past two decades (95). Individuals sustaining ACLi are predisposed to accelerated OA, and not surprisingly, injury at a young age very likely results in earlier OA development. Given this, and the fact that PTOA is a consequence of joint trauma, it is reasonable to assume that sequelae of these injuries constitute a significant amount of TKRs performed. Reducing the demand for arthroplasty is favorable, thus, the need for new strategies in OA prevention following knee injury, as well as management of early-stage $O A$, is emphasized. When ACLi has occurred, our work will be minimizing undesirable outcomes, such as joint replacement surgery, as well as informing patients about the risk. OA development after ACLi is multifactorial, but rehabilitation protocols, including neuromuscular knee exercise, should be initiated in every patient (96). Physicians and clinicians should be aware of modifiable factors that could postpone the need for KR, hence, give advice about lifestyle changes. There is a lack of knowledge in the field and patient preference of knowledge is often guided by the choice of top level athletes. This might not be the best role model for the general patient subjected to this knee injury. Further research, either from knee registries or long-term follow-up in randomized controlled trials, might be key factors to outline this warranted knowledge.

Something to consider is the trend of a higher threshold to perform joint replacement surgery in younger patients, which may underestimate the burden of disease (96). Although the absolute rate of KR following primary ACLi is relatively low, the risk of undergoing KR at a younger age is significantly increased, compared to the general population (72). Overall, available literature reporting KR among patients with 
primary ACLi is scarce, and the Coleman scorings reveal that there is room for improvement in research to outline the risk of $\mathrm{KR}$ after ACLi. Furthermore, another significant limitation in this study is omitting the length of time from ACLi to KR, which is due to the absence of this important factor in most studies. We are fully aware of the fact that a risk estimate without including the time gap between injury and KR is of less value and that a methodology showing Kaplan-Meier curve would be optimal. Nevertheless, findings in this systematic review may be helpful when counselling patients about the risk of undergoing KR after ACLi, but it is desirable with more high-quality, preferably prospective, studies with minimal variability in baseline characteristics and consistency in follow-up times, rehabilitation protocols and diagnostic techniques, as well as defining the length of time between the events.

\section{Abbreviations}

$\mathrm{ACL}=$ anterior cruciate ligament

$\mathrm{ACLi}=$ anterior cruciate ligament injury

ACLR = anterior cruciate ligament reconstruction

$A D L=$ function in daily living

$\mathrm{Cl}=$ confidence interval

CMS = Coleman Methodology Score

JSN = joint space narrowing

KOOS = Knee Injury and Osteoarthritis Outcome Score

$\mathrm{KR}=$ knee replacement

$\mathrm{MCL}=$ medial collateral ligament

$\mathrm{MT}=$ meniscal tear

MCMS $=$ Modified Coleman Methodology Score

NKLR = Norwegian Knee Ligament Registry

$\mathrm{OA}=$ osteoarthritis

PCLR = posterior cruciate ligament reconstruction

PTOA = posttraumatic osteoarthritis

QoL = quality of life 
rACLR = revision anterior cruciate ligament injury

rCLR = revision cruciate ligament reconstruction

TKA = total knee arthroplasty

$\mathrm{TKR}=$ total knee replacement

UKR = unicompartmental knee replacement

\section{Declarations}

\section{Ethics approval and consent to participate}

Not applicable.

\section{Consent for publication}

Not applicable.

\section{Availability of data and materials}

All data and materials used in this study are available online.

\section{Competing interests}

The authors declare that there is no conflict of interest.

\section{Funding}

No funding received.

\section{Authors' contributions}

MDN sampled and analyzed the data and materials. AA supervised the work. Both authors read and approved the final manuscript.

\section{Acknowledgments}

Not applicable.

\section{Authors' information}

After completely tearing my right anterior cruciate ligament at the age of 17 during a soccer match and at a time I wanted to pursue a soccer career, I was determined to undergo surgical reconstruction. Today, at the age of 23, my right knee is still missing the anterior cruciate ligament, as I, after many discussions with several orthopedic surgeons, did not choose surgical intervention due to no disabling instability symptoms. The year after the injury, I attended medical school and put away my dream of becoming a professional soccer player, but I was still worrying about my knee condition, such as will I develop knee arthrosis faster than those who undergo surgery? All of the orthopedists referred to evidence-based medicine, and I was told that recent studies have not found a conclusion that surgery is superior to 


\section{Appendix}

\section{Appendix 1. Modified Coleman Methodology Score}

Part A - only one score to be given for each of the seven sections

1. Study size - number of patients $(\mathrm{N})$

$\mathrm{N}>120$

N $81-120$

$\mathrm{N} 40-80$

$\mathrm{N}<40$ or not stated

2. Mean follow-up

$>6$ years

3-6 vears

$<3$ years, not stated, or unclear

3

3. Percent of patients with follow-up

$>90 \%$

$80-90 \%$

$<80 \%$

(radiographic and clinical)

One intervention in all patients in each group

4. Number of interventions per group

Multiple interventions but consistent

among all patients in each group

Unclear, unreported, or multiple

interventions among patients

in the same group

5. Type of study

Randomized control trial

Prospective cohort study

Retrospective cohort study

15

In all

6. Diagnostic certainty

(diagnosis confirmed by defined PE findings or MRI)

In $\geq 80 \%$

In $<80 \%$, instated, or unclear

5

7. Description of surgical technique

Technique stated with necessary details to repeat

Technique named without elaboration Not stated or unclear

Well described with $\geq 80 \%$

patient compliance

Well described with $60-80 \%$

patient compliance, or described

without complete detail

Protocol not reported $<60 \%$

patient compliance

Part B - scores may be given for each option in each of the three sections if applicable

1. Outcome criteria

2. Procedure for assessing outcomes

3. Description of subject selection process
Outcome measures clearly defined Timing of outcome assessment clear Use of outcome criteria with reported good reliability

Use of outcome with good sensitivity

Subjects recruited

Independent investigator

(2 for radiographic, 2 for clinical)

Written assessment

Patient centered data collected

Selection criteria reported and unbiased

Recruitment rate reported and $\geq 80 \%$

Eligible subjects not included in the

study satisfactorily accounted for

Total 


\section{References}

1. Boden BP, Dean GS, Feagin JA, Garrett WE. Mechanisms of anterior cruciate ligament injury. Orthopedics. 2000;23(6):573-8.

2. Ettlinger CF, Johnson RJ, Shealy JE. A method to help reduce the risk of serious knee sprains incurred in alpine skiing. The American journal of sports medicine. 1995;23(5):531-7.

3. Friedberg RP. Anterior cruciate ligament injury. UpToDate. 2019 November 18.

4. Furnes $\mathrm{O}$, Visnes $\mathrm{H}$. The Norwegian Cruciate Ligament Register.

5. AskMayoExpert. Anterior cruciate ligament (ACL) injury. Mayo Clinic. 2018.

6. Lohmander LS, Englund PM, Dahl LL, Roos EM. The long-term consequence of anterior cruciate ligament and meniscus injuries: osteoarthritis. The American journal of sports medicine. 2007;35(10):1756-69.

7. Pike AN, Patzkowski JC, Bottoni CR. Meniscal and Chondral Pathology Associated With Anterior Cruciate Ligament Injuries. J Am Acad Orthop Surg. 2019;27(3):75-84.

8. Domnick C, Raschke MJ, Herbort M. Biomechanics of the anterior cruciate ligament: Physiology, rupture and reconstruction techniques. World journal of orthopedics. 2016;7(2):82.

9. Butler D, Noyes F, Grood E. Ligamentous restraints to anterior-posterior drawer in the human knee. J Bone Joint Surg Am. 1980;62(2):259-70.

10. Eustice C. When Your Knee Gives Out. Very Well Health. 2019.

11. Louboutin H, Debarge R, Richou J, Selmi TA, Donell ST, Neyret P, et al. Osteoarthritis in patients with anterior cruciate ligament rupture: a review of risk factors. Knee. 2009;16(4):239-44.

12. Visnes H, Kroken G. Norwegian National Knee Ligament Registry - annual report 2018 with improvement plan. Bergen: Haukeland University Hospital, Helse-Bergen HF; 2019.

13. Agel J, Rockwood T, Klossner D. Collegiate ACL injury rates across 15 sports: national collegiate athletic association injury surveillance system data update (2004-2005 through 2012-2013). Clinical journal of sport medicine. 2016;26(6):518-23.

14. Ardern CL, Taylor NF, Feller JA, Webster KE. Fifty-five per cent return to competitive sport following anterior cruciate ligament reconstruction surgery: an updated systematic review and meta-analysis including aspects of physical functioning and contextual factors. $\mathrm{Br} \mathrm{J}$ Sports Med. 2014;48(21):1543-52.

15. Roos H, Ornell M, Gärdsell P, Lohmander L, Lindstrand A. Soccer after anterior cruciate ligament injury-an incompatible combination? A national survey of incidence and risk factors and a 7-year follow-up of 310 players. Acta orthopaedica Scandinavica. 1995;66(2):107-12.

16. Filbay S, Culvenor A, Ackerman I, Russell T, Crossley K. Quality of life in anterior cruciate ligamentdeficient individuals: a systematic review and meta-analysis. British journal of sports medicine. 2015;49(16):1033-41. 
17. Engebretsen L, Benum P, Fasting O, Mølster A, Strand T. A prospective, randomized study of three surgical techniques for treatment of acute ruptures of the anterior cruciate ligament. The American journal of sports medicine. 1990;18(6):585-90.

18. Ihara H, Miwa M, Deya K, Torisu K. MRI of anterior cruciate ligament healing. Journal of computer assisted tomography. 1996;20(2):317-21.

19. SkadeSiden. Invaliditetstabellen. Oslo. Retrieved 06.02.20 from https://www.skadesiden.no/artikler/nyttig2/51-invaliditetstabell.

20. Nixon JE. Acute injuries of the anterior cruciate ligament of the knee: primary repair. Bulletin of the New York Academy of Medicine. 1980;56(5):483.

21. Oliestad B, Engebretsen L, Storheim K, Risberg M. Knee osteoarthritis after anterior cruciate ligament injury. Am J Sports Med. 2009;37(7):1434-43.

22. Frobell RB, Roos HP, Roos EM, Roemer FW, Ranstam J, Lohmander LS. Treatment for acute anterior cruciate ligament tear: five year outcome of randomised trial. Bmj. 2013;346:f232.

23. Brandsson S, Karlsson J, Swärd L, Kartus J, Eriksson BI, Kärrholm J. Kinematics and laxity of the knee joint after anterior cruciate ligament reconstruction: pre-and postoperative radiostereometric studies. The American journal of sports medicine. 2002;30(3):361-7.

24. Swirtun L, Eriksson K, Renström P. Who chooses anterior cruciate ligament reconstruction and why? A 2-year prospective study. Scandinavian journal of medicine \& science in sports. 2006;16(6):441-6.

25. Tashman S, Kopf S, Fu FH. The kinematic basis of anterior cruciate ligament reconstruction. Operative techniques in sports medicine. 2012;20(1):19-22.

26. Sanders TL, Kremers HM, Bryan AJ, Fruth KM, Larson DR, Pareek A, et al. Is Anterior Cruciate Ligament Reconstruction Effective in Preventing Secondary Meniscal Tears and Osteoarthritis? Am J Sports Med. 2016;44(7):1699-707.

27. Løken S, Årøen A, Engebretsen L, Aspenberg P, Lohmander LS, Frobell RB. Overtreatment of cruciate ligament injuries. Acta orthopaedica. 2011;82(1):122-3.

28. Fleming BC, Hulstyn MJ, Oksendahl HL, Fadale PD. Ligament injury, reconstruction and osteoarthritis. Current opinion in orthopaedics. 2005;16(5):354.

29. Sommerfeldt M, Raheem A, Whittaker J, Hui C, Otto D. Recurrent instability episodes and meniscal or cartilage damage after anterior cruciate ligament injury: a systematic review. Orthopaedic journal of sports medicine. 2018;6(7):2325967118786507.

30. Lindanger L, Strand T, Molster AO, Solheim E, Inderhaug E. Return to Play and Long-term Participation in Pivoting Sports After Anterior Cruciate Ligament Reconstruction. Am J Sports Med. 2019;47(14):3339-46.

31. Sinusas K. Osteoarthritis: diagnosis and treatment. American family physician. 2012;85(1):49-56.

32. Arden N, Nevitt MC. Osteoarthritis: epidemiology. Best practice \& research Clinical rheumatology. 2006;20(1):3-25. 
33. Woolf AD, Pfleger B. Burden of major musculoskeletal conditions. Bulletin of the world health organization. 2003;81:646-56.

34. Fairbank T. Knee joint changes after meniscectomy. The Journal of bone and joint surgery British volume. 1948;30(4):664-70.

35. Neyret P, Donell S, Dejour H. Osteoarthritis of the knee following meniscectomy. Rheumatology. 1994;33(3):267-8.

36. Shelton WR, Barrett GR, Dukes A. Early season anterior cruciate ligament tears: a treatment dilemma. The American journal of sports medicine. 1997;25(5):656-8.

37. Finsterbush A, Frankl U, Matan Y, Mann G. Secondary damage to the knee after isolated injury of the anterior cruciate ligament. The American journal of sports medicine. 1990;18(5):475-9.

38. Englund $\mathrm{M}$. The role of biomechanics in the initiation and progression of $\mathrm{OA}$ of the knee. Best practice \& research Clinical rheumatology. 2010;24(1):39-46.

39. Khan T, Alvand A, Prieto-Alhambra D, Culliford DJ, Judge A, Jackson WF, et al. ACL and meniscal injuries increase the risk of primary total knee replacement for osteoarthritis: a matched case-control study using the Clinical Practice Research Datalink (CPRD). Br J Sports Med. 2019;53(15):965-8.

40. Neyret P, Donell S, Dejour H. Results of partial meniscectomy related to the state of the anterior cruciate ligament. Review at 20 to 35 years. The Journal of bone and joint surgery British volume. 1993;75(1):36-40.

41. Noyes FR, Mooar P, Matthews D, Butler D. The symptomatic anterior cruciate-deficient knee. Part I: the long-term functional disability in athletically active individuals. JBJS. 1983;65(2):154-62.

42. McDaniel JW, Dameron JT. The untreated anterior cruciate ligament rupture. Clinical orthopaedics and related research. 1983(172):158-63.

43. Kannus $P$, Järvinen M. Posttraumatic anterior cruciate ligament insufficiency as a cause of osteoarthritis in a knee joint. Clinical rheumatology. 1989;8(2):251-60.

44. Sherman MF, Warren RF, Marshall JL, Savatsky GJ. A clinical and radiographical analysis of 127 anterior cruciate insufficient knees. Clinical orthopaedics and related research. 1988;227:229-37.

45. Sommerlath K, Lysholm J, Gillquist J. The long-term course after treatment of acute anterior cruciate ligament ruptures: a 9 to 16 year followup. The American journal of sports medicine. 1991;19(2):15662.

46. Roos H, Adalberth T, Dahlberg L, Lohmander LS. Osteoarthritis of the knee after injury to the anterior cruciate ligament or meniscus: the influence of time and age. Osteoarthritis and Cartilage. 1995;3(4):261-7.

47. Kohn MD, Sassoon AA, Fernando ND. Classifications in brief: Kellgren-Lawrence classification of osteoarthritis. Springer; 2016.

48. Anderson AS, Loeser RF. Why is osteoarthritis an age-related disease? Best practice \& research Clinical rheumatology. 2010;24(1):15-26. 
49. McConnell S, Kolopack P, Davis AM. The Western Ontario and McMaster Universities Osteoarthritis Index (WOMAC): a review of its utility and measurement properties. Arthritis Care \& Research: Official Journal of the American College of Rheumatology. 2001;45(5):453-61.

50. Roos EM, Lohmander LS. The Knee injury and Osteoarthritis Outcome Score (KOOS): from joint injury to osteoarthritis. Health Qual Life Outcomes. 2003;1:64.

51. Hunter DJ, Eckstein F. Exercise and osteoarthritis. Journal of anatomy. 2009;214(2):197-207.

52. Nebelung W, Wuschech $\mathrm{H}$. Thirty-five years of follow-up of anterior cruciate ligament-deficient knees in high-level athletes. Arthroscopy. 2005;21(6):696-702.

53. Von Porat A, Roos EM, Roos H. High prevalence of osteoarthritis 14 years after an anterior cruciate ligament tear in male soccer players: a study of radiographic and patient relevant outcomes. Annals of the rheumatic diseases. 2004;63(3):269-73.

54. Lohmander L, Östenberg A, Englund M, Roos H. High prevalence of knee osteoarthritis, pain, and functional limitations in female soccer players twelve years after anterior cruciate ligament injury. Arthritis \& Rheumatism: Official Journal of the American College of Rheumatology. 2004;50(10):3145-52.

55. Wiggins AJ, Grandhi RK, Schneider DK, Stanfield D, Webster KE, Myer GD. Risk of secondary injury in younger athletes after anterior cruciate ligament reconstruction: a systematic review and metaanalysis. The American journal of sports medicine. 2016;44(7):1861-76.

56. Persson A, Fjeldsgaard K, Gjertsen J-E, Kjellsen AB, Engebretsen L, Hole RM, et al. Increased risk of revision with hamstring tendon grafts compared with patellar tendon grafts after anterior cruciate ligament reconstruction: a study of 12,643 patients from the Norwegian Cruciate Ligament Registry, 2004-2012. The American journal of sports medicine. 2014;42(2):285-91.

57. Grotle M, Hagen KB, Natvig B, Dahl FA, Kvien TK. Prevalence and burden of osteoarthritis: results from a population survey in Norway. J Rheumatol. 2008;35(4):677-84.

58. NTNU. The HUNT Study - a longitudinal population health study in Norway. Nord-Trøndelag1984.

59. Leroux T, Ogilvie-Harris D, Dwyer T, Chahal J, Gandhi R, Mahomed N, et al. The risk of knee arthroplasty following cruciate ligament reconstruction: a population-based matched cohort study. JBJS. 2014;96(1):2-10.

60. Zeni JA, Jr., Axe MJ, Snyder-Mackler L. Clinical predictors of elective total joint replacement in persons with end-stage knee osteoarthritis. BMC Musculoskelet Disord. 2010;11:86.

61. Culliford D, Maskell J, Kiran A, Judge A, Javaid M, Cooper C, et al. The lifetime risk of total hip and knee arthroplasty: results from the UK general practice research database. Osteoarthritis and cartilage. 2012;20(6):519-24.

62. Carr AJ, Robertsson O, Graves S, Price AJ, Arden NK, Judge A, et al. Knee replacement. The Lancet. 2012;379(9823):1331-40.

63. Lützner J, Kasten P, Günther K-P, Kirschner S. Surgical options for patients with osteoarthritis of the knee. Nature Reviews Rheumatology. 2009;5(6):309. 
64. Bruyère 0 , Pavelka K, Rovati L, Gatterova J, Giacovelli G, Olejarova M, et al. Total joint replacement after glucosamine sulphate treatment in knee osteoarthritis: results of a mean 8-year observation of patients from two previous 3-year, randomised, placebo-controlled trials. Osteoarthritis and Cartilage. 2008;16(2):254-60.

65. Raynauld J-P, Martel-Pelletier J, Haraoui B, Choquette D, Dorais M, Wildi LM, et al. Risk factors predictive of joint replacement in a 2-year multicentre clinical trial in knee osteoarthritis using MRI: results from over 6 years of observation. Annals of the rheumatic diseases. 2011;70(8):1382-8.

66. Furnes O, Hallan G, Kroken G, Fenstad AM. Norwegian Arthroplasty Register - annural report 2018 with improvement plan. Bergen: Haukeland University Hospital, Helse-Bergen HF; 2019.

67. Meehan WP, Weisskopf MG, Krishnan S, McCracken C, Zafonte R, Taylor HA, et al. Relation of Anterior Cruciate Ligament Tears to Potential Chronic Cardiovascular diseases. Am J Cardiol. 2018;122(11):1879-84.

68. Sporsheim AN, Gifstad T, Lundemo TO, Engebretsen L, Strand T, Molster A, et al. Autologous BPTB ACL Reconstruction Results in Lower Failure Rates Than ACL Repair with and without Synthetic Augmentation at 30 Years of Follow-up: A Prospective Randomized Study. J Bone Joint Surg Am. 2019;101(23):2074-81.

69. Elveos MM, Drogset JO, Engebretsen L, Brønn R, Lundemo TO, Gifstad T. Anterior cruciate ligament reconstruction using a bone-patellar tendon-bone graft with and without a ligament augmentation device: a 25-year follow-up of a prospective randomized controlled trial. Orthopaedic journal of sports medicine. 2018;6(11):2325967118808778.

70. Gfoller P, Abermann E, Runer A, Hoser C, Pfluglmayer M, Wierer G, et al. Non-operative treatment of ACL injury is associated with opposing subjective and objective outcomes over 20 years of followup. Knee Surg Sports Traumatol Arthrosc. 2019;27(8):2665-71.

71. Hagmeijer MH, Hevesi M, Desai VS, Sanders TL, Camp CL, Hewett TE, et al. Secondary Meniscal Tears in Patients With Anterior Cruciate Ligament Injury: Relationship Among Operative Management, Osteoarthritis, and Arthroplasty at 18-Year Mean Follow-up. Am J Sports Med. 2019;47(7):1583-90.

72. Abram SGF, Judge A, Khan T, Beard DJ, Price AJ. Rates of knee arthroplasty in anterior cruciate ligament reconstructed patients: a longitudinal cohort study of 111,212 procedures over 20 years. Acta Orthop. 2019;90(6):568-74.

73. Singhal MC, Gardiner JR, Johnson DL. Failure of primary anterior cruciate ligament surgery using anterior tibialis allograft. Arthroscopy. 2007;23(5):469-75.

74. Sanders TL, Pareek A, Kremers HM, Bryan AJ, Levy BA, Stuart MJ, et al. Long-term follow-up of isolated ACL tears treated without ligament reconstruction. Knee Surg Sports Traumatol Arthrosc. 2017;25(2):493-500.

75. Lin SH, Wang TC, Lai CF, Tsai RY, Yang CP, Wong CS. Association of anterior cruciate ligament injury with knee osteoarthritis and total knee replacement: A retrospective cohort study from the Taiwan National Health Insurance Database. PLoS One. 2017;12(5):e0178292. 
76. Boyle C, Pagoti R, Eng KH, McMahon SE, Nicholas R. Revision ACL reconstruction with autograft: long-term functional outcomes and influencing factors. Eur J Orthop Surg Traumatol. 2019;29(1):157-61.

77. Coleman B, Khan K, Maffulli N, Cook J, Wark J. Studies of surgical outcome after patellar tendinopathy: clinical significance of methodological deficiencies and guidelines for future studies. Scandinavian Journal of Medicine \& Science in Sports: Review article. 2000;10(1):2-11.

78. Jakobsen RB, Engebretsen L, Slauterbeck JR. An analysis of the quality of cartilage repair studies. JBJS. 2005;87(10):2232-9.

79. Watsend AME, Osestad TM, Jacobsen RB, Engebretsen L. Clinical studies on posterior cruciate ligament tears have weak design. Knee surgery, sports traumatology, arthroscopy. 2009;17(2):140-9.

80. Aanstad M. Prognosen for full retur etter kirurgisk rekonstruksjon av fremre korsbånd til samme idrettsnivå som før ruptur ser ut til å være dårligere enn tidligere antatt 2018.

81. Van Tulder MW, Touray T, Furlan AD, Solway S, Bouter LM. Muscle relaxants for nonspecific low back pain: a systematic review within the framework of the cochrane collaboration. Spine. 2003;28(17):1978-92.

82. Kalla S. Statistical Significance And Sample Size. 2009.

83. Aalen 00. Statistiske metoder i medisin og helsefag: Gyldendal Norsk Forlag; 2006.

84. Patel MX, Doku V, Tennakoon L. Challenges in recruitment of research participants. Advances in Psychiatric Treatment. 2003;9(3):229-38.

85. DePaulo P. Sample size for qualitative research. Quirks Marketing Research Review. 2000;1202.

86. Shane Anderson A, Loeser RF. Why is osteoarthritis an age-related disease? Best Pract Res Clin Rheumatol. 2010;24(1):15-26.

87. Ajuied A, Wong F, Smith C, Norris M, Earnshaw P, Back D, et al. Anterior cruciate ligament injury and radiologic progression of knee osteoarthritis: a systematic review and meta-analysis. Am J Sports Med. 2014;42(9):2242-52.

88. Chapple CM, Nicholson H, Baxter GD, Abbott JH. Patient characteristics that predict progression of knee osteoarthritis: a systematic review of prognostic studies. Arthritis Care Res (Hoboken). 2011;63(8):1115-25.

89. Roos H, Lauren M, Adalberth T, Roos EM, Jonsson K, Lohmander LS. Knee osteoarthritis after meniscectomy: prevalence of radiographic changes after twenty-one years, compared with matched controls. Arthritis and rheumatism. 1998;41(4):687-93.

90. Papalia R, Del Buono A, Osti L, Denaro V, Maffulli N. Meniscectomy as a risk factor for knee osteoarthritis: a systematic review. British medical bulletin. 2011;99:89-106.

91. Weber J, Koch M, Angele P, Zellner J. The role of meniscal repair for prevention of early onset of osteoarthritis. Journal of experimental orthopaedics. 2018;5(1):10.

92. Englund M, Lohmander LS. Meniscectomy and osteoarthritis: what is the cause and what is the effect? International Journal of Clinical Rheumatology. 2006;1(2):207. 
93. Leininger RE, Knox CL, Comstock RD. Epidemiology of 1.6 million pediatric soccer-related injuries presenting to US emergency departments from 1990 to 2003. The American journal of sports medicine. 2007;35(2):288-93.

94. Owings M. Ambulatory and inpatient procedures in the United States, 1996: US Department of Health and Human Services, Centers for Disease Control and ...; 1998.

95. Beck NA, Lawrence JTR, Nordin JD, DeFor TA, Tompkins M. ACL tears in school-aged children and adolescents over 20 years. Pediatrics. 2017;139(3):e20161877.

96. Neuman P, Englund M, Kostogiannis I, Friden T, Roos H, Dahlberg LE. Prevalence of tibiofemoral osteoarthritis 15 years after nonoperative treatment of anterior cruciate ligament injury: a prospective cohort study. The American journal of sports medicine. 2008;36(9):1717-25.

\section{Figures}

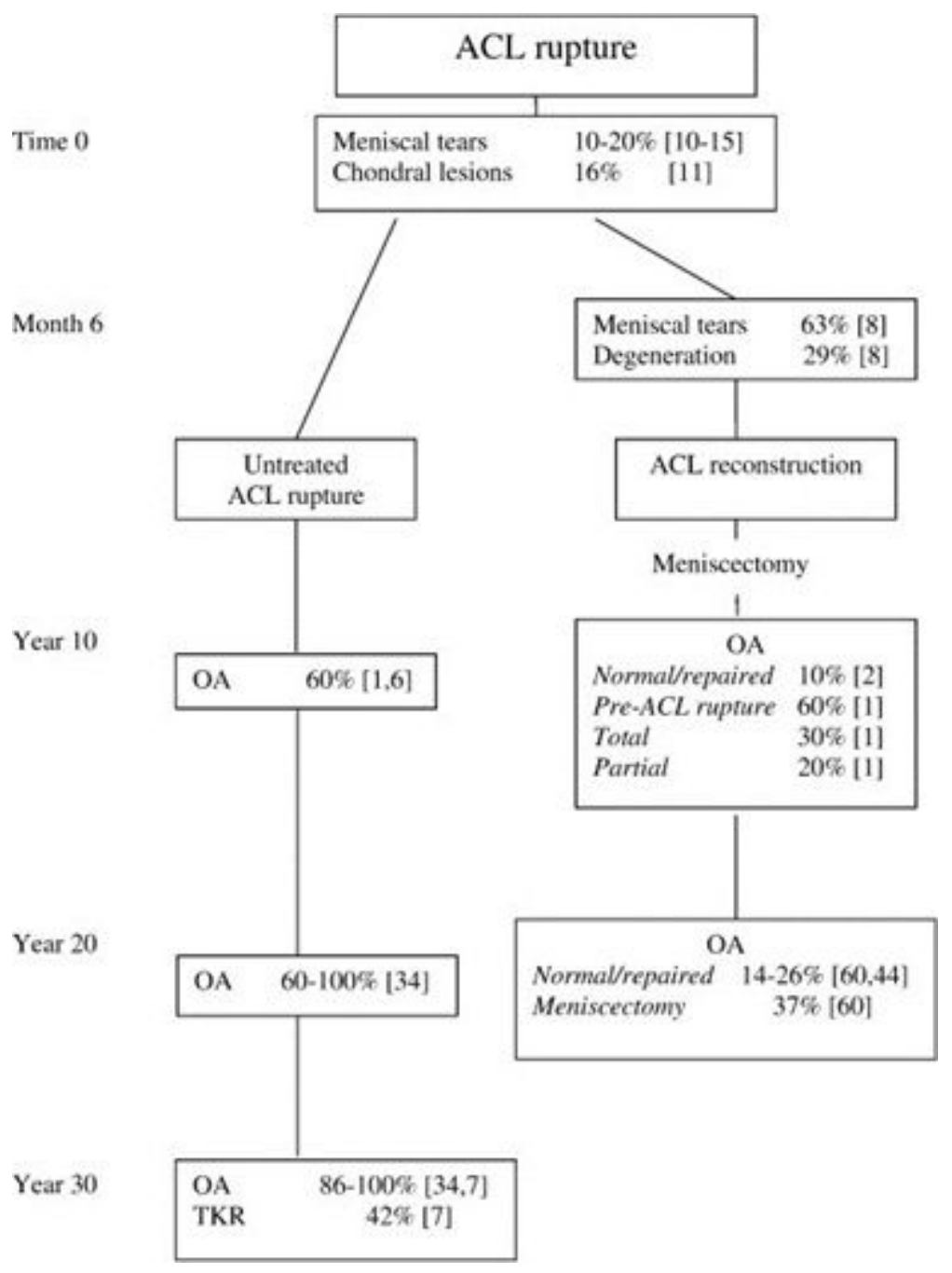

Figure 1

Figure from Louboutin et al. (2009) showing a summary of OA rates following ACLi in 19 elite sport athletes (11). This is consistent with OA being a chronic disease progressing over time and that OA 
development is accelerated by high activity. Furthermore, this cohort study shows a protective role of ACLR, which may be explained by the reduced risk of secondary MT and/or chondral lesions when participating in elite sport

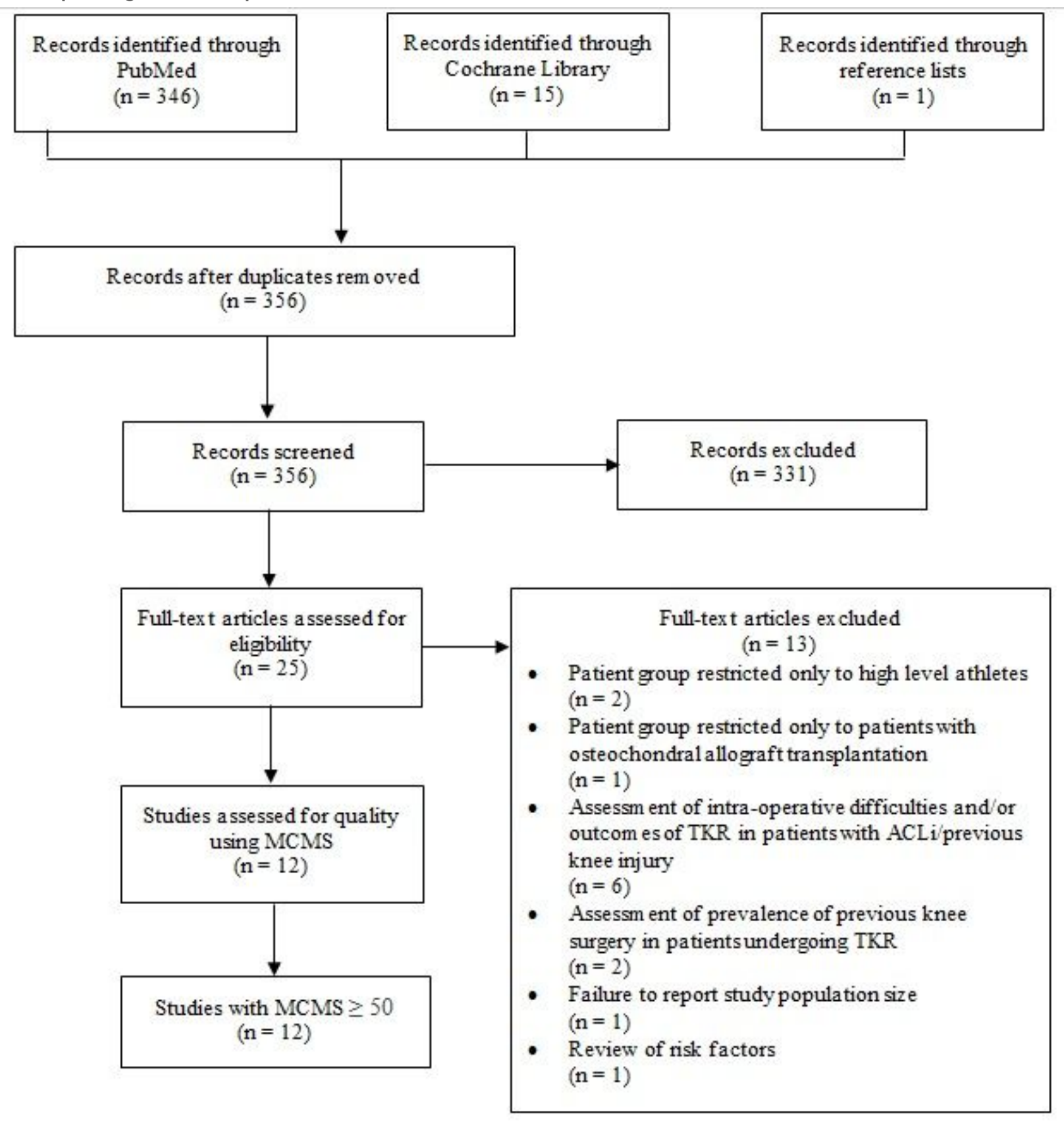

Figure 2

Flow chart showing the study selection 


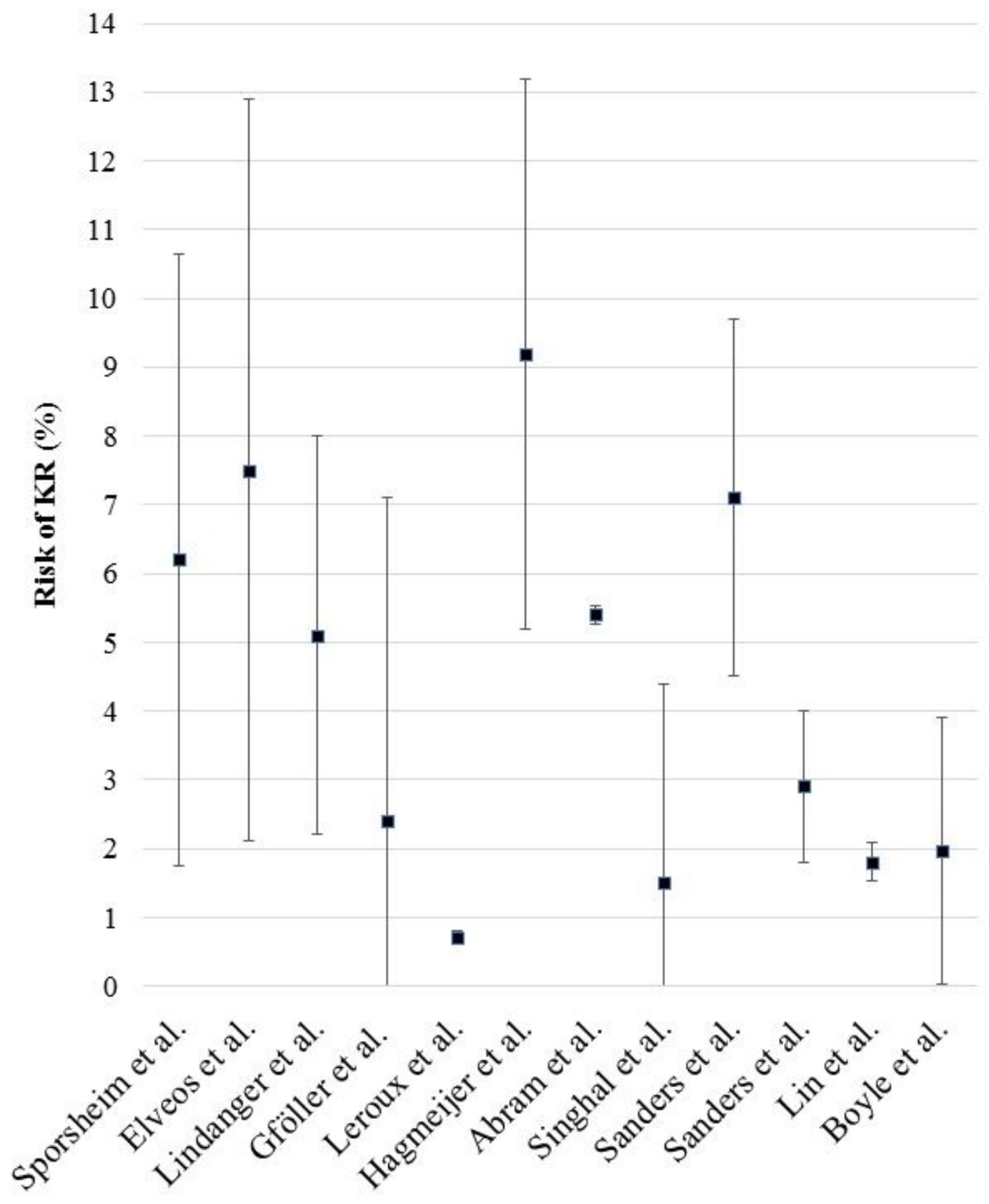

Figure 3

Estimated risk of KR (\%) among patients with a history of primary ACLi, as well as $95 \% \mathrm{Cl}$, for each included study

\section{Supplementary Files}

This is a list of supplementary files associated with this preprint. Click to download. 
- PRISMA2009checklist.doc 